\title{
ELEMENTOS DO CULTO À POMBAGIRA MARIA PADILHA: A POSIÇÃO SIMBÓLICA DA MULHER NA RELIGIÃO AFRO-BRASILEIRA
}

\author{
Gabriel Felipe Montes Lima ${ }^{1}$
}

RESUMO: O presente artigo se propõe a analisar a posição simbólica do feminino na sociedade brasileira contemporânea com foco nas religiões afro-brasileiras. Acima de tudo, analisamos a evolução social do culto à pombagira Maria Padilha como uma amostra da ascensão social feminina, que ocupa um lugar de sacralidade através desse simbolismo. Percebeu-se, mediante análise bibliográfica, que houve uma transição psicanalítica entre a mulher cristã Maria (sacralizada por meio de Jesus) e a posição da pombagira (que simboliza o sagrado feminino aproximado às esferas marginalizadas da sociedade) de modo que a liberdade e autonomia feminina são mais presentes no contexto das religiões afro-brasileiras.

Palavras-Chave: Pombagira. Maria Padilha. Religião Afro-Brasileira. Feminilidade.

\section{I.INTRODUÇÃO}

A evolução do culto às pombagiras no Brasil significa, sobre tudo, a ascensão social da posição da mulher no país. Isso porque, na medida em que a mulher pôde ser (re)sacralizada no âmbito do próprio feminino sem recorrer a arquétipos maternos, podemos encarar que o lugar do feminino como um todo principia a sofrer uma transição de posição simbólica para fora da lógica fálico/ não-fálico. Nesse sentido, a mulher-pombagira deixa de ser observada como um ente subserviente ao homem (como observado no cristianismo tradicional, no qual Maria é sacralizada através de um objeto fálico: seu filho, Jesus) e assume uma posição de sujeito ativo e

${ }^{\mathrm{I}}$ Graduação em andamento em Letras- Habilitação em Português e Espanhol e Respectivas Literaturas pela Universidade Federal de Mato Grosso (UFMT) e em História pela Unyleya. Formação em Psicanálise Clínica pelo Instituto Brasileiro de Psicanálise Clínica. Atualmente é colunista na revista oficial do IBPC e no Jornal Tribuna. Tem experiência na área de Letras, História e Psicanálise, com ênfase em Literatura Comparada e História da Arte. Também possui ampla experiência em línguas estrangeiras antigas e modernas. No momento, se dedica a atividades ligadas à escrita criativa, estudos de literatura comparada sob perspectivas históricas, psicanálise e estudos de gênero. E-mail: gabrielfelipeo3o8@gmail.com 
autônomo. Não em vão, a nomenclatura "rainha" é empregada para os fiéis se referirem às pombagiras como um todo. Mais especificamente, a entidade Maria Padilha é um ícone muito presente tanto dentro quanto fora do ambiente religioso das matrizes africanas.

Essa transição de identidade marca não apenas a visão religiosa sobre a mulher, mas também, e fundamentalmente, assinala a possibilidade de se (re)pensar a religiosidade brasileira como um todo. Dessa forma, a aparição dessa forma de se simbolizar o feminino destaca a desconstrução de um pensar machista no âmbito religioso.

Com efeito, deve-se esclarecer que o olhar para o feminino como "não-fálico" não era presente nas culturas iorubás, das quais derivaram as religiões afrobrasileiras, como o Candomblé, a Umbanda, a Kimbanda e a linha Xangô. Essa percepção foi produto de um intercâmbio cultural entre África e Europa e, mais objetivamente, entre as Religiões Tribais e o Cristianismo.

É, pois, desnecessário apontar as enormes divergências que haviam entre essas diversas formas de se conceber e estar no mundo. No entanto, cabe dizermos que a sobrevivência dos principais aspectos da religiosidade africana apenas puderam sobreviver e, quiçá, prosperar de algum modo até a abolição da escravidão se deve, de fato, à assimilação de aspectos cristãos que ocorreu com essas religiões no processo de sincretismo religioso.

De um modo geral, a título de esclarecimento, as religiões afro-americanas detentoras de maior número de fiéis são a Umbanda e o Candomblé. A distinção fundamental entre elas se estabelece no grau de preservação das tradições africanas. Assim, no Candomblé se encontram melhor preservados os ritos tradicionais da África Pré-Diáspora e, na Umbanda, esses aspectos se encontram mais miscigenados com elementos da cultura local. (PRANDI, 2021) 


\subsection{A Pombagira}

Essencialmente, o termo Pombagira sofreu alguns câmbios ao longo do contato intercultural entre africanos e europeus. No entanto, o aspecto de mulheres "sedutoras, feiticeiras, eróticas e sábias, (no qual) tais personagens abarcam ascendências diversas que se combinam em imagens de femininos subversivos" (BARROS, 2013, p.509) persiste em todas as abordagens acerca dessas entidades. As pombagiras não são passíveis de uma concepção linear de identidade. Pelo contrário, um de seus aspectos mais marcantes é a ambiguidade. Não se ode definir Maria Padilha como boa ou má, pois, ao mesmo tempo em que ela é mencionada como gentil e amorosa, a entidade é vista como vingativa e perigosa. Vide Abre A Roda (MUSIXMATCH, 202i) de Manoel de Exú:

"Abre a roda

Oi deixa Maria Padilha dançar

Mas ela tem dois amores ao seu lado,

Um é seu marido e outro é seu namorado,

Mas cuidado moço eu vou te falar qual é

Ela é mulher de trança ruas e amante do Seu Zé

Mas ela linda,

é linda ela é linda demais Maria Padilha ela é mulher de satanás

Não mexa com ela, ela não mexe com ninguém

Ela é ponta de agulha e quando mexe, mexe bem

Não mexa com ela, ela não mexe com ninguém

Ela é ponta de agulha e quando mexe, mexe bem.”

De um modo análogo, como pode-se perceber, a fidelidade, monogamia e castidade, aspectos tipicamente associados à mulher cristã são de pouca relevância quando observamos a natureza atribuída à Maria Padilha.

\subsection{Os Elementos Simbólicos da Pombagira}

a) A Rosa

Dentro de uma análise semiótica, a rosa costuma ser representante da sensualidade feminina ao mesmo tempo em que evoca a sensualidade envolta no 
mistério. Esse elemento é muito presente em praticamente todos os cultos consagrados às pombagiras.

b) O Cigarro

O cigarro deve ser observado por meio da perspectiva social da religião afrobrasileira. Isto é, o cigarro é a transliteração direta da presença sociocultural da população marginalizada para o contexto religioso. Assim como se acendem incensos para Hécate ou Lakshmi, assim se acendem cigarros em oferenda às pombagiras.

Em uma perspectiva mais próxima da religiosidade, nos valemos da explicação de C.E.O. Estela Guia (2021):

“O fumo é vegetal que traz os elementos água e terra, em sua composição, e os elementos ar e fogo quando utilizado na defumação. Conjuga, portanto, quando usado pelas entidades de Umbanda, os quatro elementos básicos - água, terra, fogo, ar -, além do elemento vegetal nos trabalhos de magia. O fumo é utilizado como meio de descarrego, agindo sobre os chacras das pessoas. É utilizado como componente para defumação, onde conjuga o fogo e a fumaça para a destruição dos campos magnéticos negativos, vinculados tanto à obsessões quanto à demandas realizadas contra quem quer que seja."

c) A Bebida

Dentro de uma análise transversal, a bebida pode ser compreendida na mesma posição simbólica do cigarro. A bebida ocupa a posição de sacrifício à Pombagira ao mesmo tempo em que funciona como um elemento de descarrego energético e purificador do corpo do médium.

Normalmente, se oferecem bebidas leves às pombagiras, como vinho e champagne; e se reservam os produtos mais fortes, como marafo aos exús.

\subsection{Assimilação Cultural do Nome Maria Padilha e Outros Elementos Estrangeiros}

"Meyer, autora de uma análise da pombagira Maria Padilha que remonta às feiticeiras dos séculos XVI e XVII (...) ressalta de estudos multidisciplinares e específicos sobre a pombagira" (BARROS \& BAIRÃO, 2015). Originalmente, Maria Padilha foi o nome da mulher nascida em 1334 que passou de:

“amante a rainha, Maria Padilla influenciou o rei Dom Pedro I de Castela (1334-1369) nas mais importantes decisões, além de determinar o modo 
como governaria e auxiliar na negociação de seu casamento com Branca de Bourbon, visando uma aliança com a França.

Também conhecida como Maria de Padilla, a amante do rei de Castela teve com ele quatro filhos. Contam que estava prestes a dar à luz quando Branca de Bourbon chegou para selar o acordo de casamento. Três dias depois da cerimônia, o rei desfez a aliança com os franceses, abandonou a esposa e retornou para os braços de sua a amada." (RODNEY, 2018).

Posteriormente, no século XIX, na corte de D.Pedro II, uma mulher mestiça recebeu uma entidade feiticeira em uma sessão de Catimbó que se apresentou como Rainha Maria Padilha de Castela.

“ (Ela) contou sua história e disse que depois dela outras Padilhas viriam para fazer parte da sua quadrilha. Depois dessa anunciação de D. Maria Padilha, ela só voltou pouquíssimas vezes, e que, não mais chegaria a terra por sua missão presente estar cumprida, mas, que por castigo de Jesus e por mando do Rei das Encruzilhadas ela ainda permaneceria na terra e confins, comandando a sua quadrilha de mulheres e exus para todos os ti de trabalhos. Depois disso, nunca mais ninguém voltou a ver ou assistir a curimba desta poderosa entidade rainha das giras." (MOLINA, 202I).

Essa elaboração histórica denota a presença de uma assimilação cultural marcada pela conversão da identidade pessoal. Isto é, Maria Padilha (entidade) não representa necessariamente um vínculo direto com a rainha de Castela Maria Padilha. Pelo contrário, a figura da rainha funciona como um elo simbólico que confere valor à figura da pombagira Maria Padilha. Isso significa dizer que a rainha de Castela e a Pombagira estão ligadas assimetricamente, na medida em que a pombagira se arvora sobre a figura da Rainha (enquanto arquétipo) e da Deusa funcionando como uma transliteração d'Ela para a realidade sociocultural brasileira. Contudo, a rainha de Castela Maria Padilha não possuiu uma relação com o culto às pombagiras (incluso por questões temporais que os dividiam). Entender esse fenômeno possibilita uma leitura teórica e teológica para uma realidade que é, antes de qualquer coisa, do universo da fideo e, por isso, divorciada da necessidade de uma comprovação científica.

\subsection{O Culto de Maria Padilha}

Assim como o que ocorre com o complementar masculino (Exú), as Pombagiras possuem diversas nomenclaturas entre si, diferenciando-se em certa 
medida umas das outras. De modo geral, pode-se conceber que Pombagira é um termo macro que engloba muitas entidades, como Maria Mulambo, Rosa Vermelha, Rosa Caveira, Sete-Saias, Pombagira Menina etc. Do mesmo modo, há muitas Marias Padilhas, como Maria Padilha das Almas e Maria Padilha das Sete Encruzilhadas. Todavia, trataremos todas as subdiferenciações do nome como parte da integralidade.

Essa entidade, como afirmado, é frequentemente relacionada à rainha de mesmo nome, como se pode observar na canção Salve Maria Padilha interpretada Manuel de Exu (2019).

\footnotetext{
"Naquela bela noite de luar, deslumbrei sua dança

Com sua saia a rodar, eu me aproximei

E lhe perguntei o que ela fazia na estrada

Ela respondeu: Moço eu sou Rainha, vim lhe ajudar

Sou Maria Padilha

Ela respondeu: Moço eu sou Rainha, vim lhe ajudar

Sou Maria Padilha"
}

Outro elemento associado à Pombagira lato sensu e à toda Linha da Esquerda dentro da Umbanda é o mistério da vida e da morte. Desse modo, essas entidades são frequentemente relacionadas à Calunga (cemitério), como se pode observar no ponto Abre Essa Cova (Cifraclub, 202I)

\footnotetext{
"Abre essa cova

Quero ver tremer

Abre essa cova quero ver balancear

Maria Padilha das almas

O cemitério é o seu lugar

É na Calunga que a Padilha mora

É na Calunga que a Padilha vai girar”
}

De um modo geral, Maria Padilha está ligada diretamente ao Mistério. Ela guarda o segredo da vida e da morte e subverte o conceito de Bem e Mal, levando-nos ao questionamento de uma lógica binária, que é propriamente ligada ao Cristianismo. A Pombagira é um ser dual e, como tal, não podemos defini-la por meio de 
associações de cunho maniqueísta. Esse é um fator que, malgrado complexifique sua natureza, torna-a mais próxima de seus fiéis, pois a entidade assume características que a distanciam de um Sagrado distante e perfeito para aproxima-la da humanidade daqueles que seguem em seu culto.

Sensualidade, emoções complexas, atitudes liberais e comportamento dual são características sumamente presentes na humanidade. Aqui, o próprio eixo psicanalítico dos sujeitos (querer versus desejar) assume certa posição de destaque na medida em que a Pombagira é tão dual quanto o Humano. Isso porque a Linha da Esquerda, na qual trabalha Maria Padilha é uma representação simbólica do próprio homem. Não em vão, a cultura popular associou o mistério das pombagiras ao amor e ao desejo. Pelo contrário, há algo de muito assertivo nesse parecer, pois, embora a Pombagira não seja uma "mulher frívola e apaixonada" ela está profundamente ligada à emocionalidade e ao desejo.

Entrementes, a conjunção simbólica da Pombagira se entrelaça diretamente com o diálogo humano de Eros e Tanatos. Isto é, da relação complementar entre morte e erotismo como mistérios de um Inconsciente ignorado.

\subsection{Um Olhar Psicanalítico Para a Evolução do Culto de Maria Padilha}

Volver o olhar para fora do eixo europeu de religiosidade e feminilidade significa uma expansão do olhar do pesquisador. Por isso, observar o percurso feito pela sociedade brasileira sem ter como base apenas a cultura europeia é um estudo que aproxima sobremaneira a teoria da realidade.

A Pombagira é, como todo signo religioso, um arquétipo. E seu arquétipo está intimamente atrelado à imagem da Bruxa: a mulher livre, forte e autoconsciente de sua posição sociocultural. Isto é, num panorama social marcado pela misoginia, uma mulher que tenha consciência de sua posição e seja capaz de valer-se de sua própria posição de fragilidade para sobressair-se sobre o masculino representa uma ameaça à lógica patriarcal já estabelecida. Talvez daí advenha o temor popular à figura das pombagiras. 
Essencialmente, a díade Exú-Pombagira não é antagônica, mas complementar; o que significa que cada um preserva sua liberdade e sacralidade de modo independente. Esse elemento, embora amplamente presente nas culturas iorubás, significa uma evolução no panorama religioso brasileiro dominado pelo cristianismo patriarcal. Mais do que uma transição e uma "tradução" de uma cultura para outra, a presença de tais elementos advindos da África para a América significa um marco sociocultural. Ou seja, o intercâmbio de povos e culturas favorecido pela diáspora da escravidão legou profundas marcas em toda cultura brasileira. Uma delas é o culto à Pombagira, que oferece um olhar renovado e libertador para a figura da mulher como um sujeito autônomo.

Falar de Maria Padilha como entidade cultuada nas religiões de matriz africana é falar sobre o que há de mais humano no Sagrado e mais sagrado no Humano, pois a mulher Rainha e Marginal se condensam na figura dessa pombagira e trazem para o íntimo das comunidades um contato que é ancestral e inerente ao sujeito com o Sagrado Feminino. Maria Padilha é uma transliteração direta da Sacra Femina para o contexto sociocultural de uma América marcada por antagonismos sociais, políticos, históricos e culturais que remontam a fatos transcorridos a mais de quinhentos anos.

\section{CONCLUSÃO}

No presente estudo objetivamos descrever e analisar pela ótica da psicanálise o culto às pombagiras no Brasil contemporâneo. Mais especificamente, nos focamos na entidade de nome Maria Padilha. Observamos que a pombagira é uma figura ambígua que representa a individualidade subjetiva e a liberdade feminina. Nosso estudo se valeu de extratos diretos da religiosidade afro-brasileira. Esses extratos se estenderam por músicas tradicionais (pontos), textos religiosos e livros de teologia umbandista.

Naturalmente, um olhar que verse sobre um universo tão plural quanto as tradições iorubás no Brasil não se pode restringir à visão da Umbanda acerca do 
tema. No entanto, uma vez que as matrizes mais tradicionais, como o Catimbó e o Candomblé possuem uma literatura restrita sobre o tema, bem como uma tradição mais introspectiva no tocante à sua teologia e ritualística, optamos por utilizar os materiais colhidos da linha umbandista. Isso, porém, não significa de modo algum uma limitação teórica sobre o tema, senão que implica apenas um viés distinto para com o olhar do pesquisador sobre o tema.

Nesse sentido, pudemos também observar, por intermédio da Umbanda, a presença e a evolução do culto à Pombagira na contemporaneidade brasileira. Nosso estudo averiguou que o arquétipo da Pombagira e, mais especificamente da entidade Maria Padilha, representa um olhar renovado e adaptado à brasilidade dos mitos tradicionais relacionados ao Sagrado Feminino. Assim, a pombagira desempenha um papel de aproximação sociocultural entre a população marginalizada e o Sagrado ao mesmo tempo em que preserva o papel de sacralidade da mulher no contexto cultural do país. Isso nos leva a concluir que a evolução do culto à Maria Padilha e às pombagiras perfaz um percurso simbólico que sustenta a ascensão política, cultural e social da mulher no Brasil. Esse aspecto é dual, pois, no contexto tradicional iorubá, a distinção de gênero não era tão evidente quanto no contexto judaico-cristão brasileiro, logo o empoderamento feminino na África Pré-Diáspora era um aspecto evidente. No entanto, no Brasil, o crescimento no poder da mulher é um fato recente e a evolução de tal culto acompanhou esse processo.

\section{REFERÊNCIAS BIBLIOGRÁFICAS}

BARROS, Mariana Leal de \& BAIRÃO, José Francisco Miguel Henriques. Performances de gênero na umbanda: a pombagira como interpretação afro-brasileira de "mulher"?. [Online]. Disponível em: 〈https://www.scielo.br/j/rieb/a/X4H65Gj37NQqctdySqMGS5c/?format=html\#〉. Acesso em : 15 de Outubro de 2021. 
BARROS, Mariana Leal de. "Os deuses não ficarão escandalizados" ascendências e reminiscências de femininos subversivos no sagrado. Revista Estudos Feministas, v. 21, p. 509-534, 2013.

CIFRACLUB. Abre Essa Cova. [Online]. Disponível em: https://m.cifraclub.com.br/umbanda/abre-essa-cova/letra/. Acesso em: is de Outubro de 202I.

C.E.O. Estela Guia. Por Que Usa-se Fumo na Umbanda?. Disponível em: https://ceuestrelaguia.org.br/por-que-usa-se-fumo-na-umbanda/. Acesso em o2 de Novembro de 2021.

MEYER, Marlyse. Maria Padilha e toda a sua quadrilha: de amante de um rei de Castela a pombagira de umbanda, São Paulo: Duas Cidades, I993.

MOLINA, N. A. Saravá Pomba-Gira Maria Padilha Encantos e Feitiços. Disponível em: https://www.lojaassombrada.com.br/livros/sarava-pomba-gira-maria-padilhaprd.html. Acesso em 02 de Novembro de 202I.

MUSIXMATCH. Manoel de Exu. [Online]. Disponível em: $\langle$ https://www.musixmatch.com/pt-br/artist/Manoel-do-Exu〉. Acesso em 2I de Outubro de 2021.

PRANDI, Reginaldo. As Principais Características do Candomblé. [online]. Disponível em: https://youtu.be/cq5dI39d8JY. Acesso em 23 de Outubro de 202I. RODNEY, Pai. Maria Padilha: Ela é Bonita, Ela é Mulher. 2018. Disponível em: <https://www.google.com/amp/s/www.cartacapital.com.br/blogs/dialogos-da$\mathrm{fe} /$ maria-padilha-ela-e-bonita-ela-e-mulher/amp/>. Acesso em is de Outubro de 2021.

TRATORE, Pontos de Maria Padilha. [Online] Disponível em: $\langle$ https://www.tratore.com.br/um_cd.php?id=I66i6〉. Acesso em: in de Outubro de 202I. 